\title{
On the Role of Eddies and Surface Forcing in the Heat Transport and Overturning Circulation in Marginal Seas
}

\author{
Michael A. SPALL \\ Woods Hole Oceanographic Institution, Woods Hole, Massachusetts
}

(Manuscript received 12 October 2010, in final form 31 January 2011)

\begin{abstract}
The factors that determine the heat transport and overturning circulation in marginal seas subject to wind forcing and heat loss to the atmosphere are explored using a combination of a high-resolution ocean circulation model and a simple conceptual model. The study is motivated by the exchange between the subpolar North Atlantic Ocean and the Nordic Seas, a region that is of central importance to the oceanic thermohaline circulation. It is shown that mesoscale eddies formed in the marginal sea play a major role in determining the mean meridional heat transport and meridional overturning circulation across the sill. The balance between the oceanic eddy heat flux and atmospheric cooling, as characterized by a nondimensional number, is shown to be the primary factor in determining the properties of the exchange. Results from a series of eddy-resolving primitive equation model calculations for the meridional heat transport, overturning circulation, density of convective waters, and density of exported waters compare well with predictions from the conceptual model over a wide range of parameter space. Scaling and model results indicate that wind effects are small and the mean exchange is primarily buoyancy forced. These results imply that one must accurately resolve or parameterize eddy fluxes in order to properly represent the mean exchange between the North Atlantic and the Nordic Seas, and thus between the Nordic Seas and the atmosphere, in climate models.
\end{abstract}

\section{Introduction}

The general ocean circulation transports heat and other tracers in the upper ocean from low latitudes to high latitudes. The heat released to the atmosphere results in dense water formation, which in turn initiates the downwelling limb of the meridional overturning circulation. This vertical circulation and meridional heat transport are fundamental components of the oceanic circulation, and play important roles in the global climate system. Understanding how this circulation depends on the environmental parameters of the system is important if one is to better model and predict the climate system and its sensitivity to changing atmospheric conditions, such as increasing anthropogenic carbon dioxide, changing ice cover, or changing storm tracks. It is also important to understand what processes need to be explicitly resolved or parameterized in climate models in

Corresponding author address: Michael Spall, MS \#21, Woods Hole Oceanographic Institution, 360 Woods Hole Rd., Woods Hole, MA 02543.

E-mail: mspall@whoi.edu order to properly represent water mass transformation and overturning at high latitudes.

Estimates of the mass transport, downwelling transport, and density of convective waters and exported waters formed in a marginal sea subject to specified buoyancy forcing can be obtained from the environmental parameters by making use of geostrophic balance, mass balance, heat balance in the basin interior, and heat balance in the marginal sea (Spall 2004; Straneo 2006; Iovino et al. 2008). A key step in this formulation is that the interior of the marginal sea is not connected to the open ocean along geostrophic contours and, as a result, mean advection of warm water from the open ocean into the interior of the marginal sea is small. This requires an additional constraint that relates the heat flux into the basin interior to that in the boundary current through a parameterization of eddy fluxes. The resulting theory compares well with eddy-resolving numerical model calculations over a wide range of parameter space. Note, however, that these models do not allow for feedback between the regions of dense water formation and the stratification of the waters outside the marginal sea. It is implicitly assumed that sufficient mixing energy exists outside the marginal sea to heat 
and restratify the inflowing waters to some specified profile.

A limitation of the studies by Spall (2004) and Iovino et al. (2008) is that their models were forced with a specified buoyancy flux in the marginal sea and did not consider wind forcing. Wind forcing was neglected for simplicity, but it is not clear from any a priori analysis that it can generally be neglected. The buoyancy flux was imposed in order to demonstrate that changes in the properties of the exchange between the marginal sea and the open ocean were due only to changes in the configuration in the basin, not due to changes in the heat loss to the atmosphere. However, this configuration fixes a climatologically important quantity, the heat flux from the marginal sea to the atmosphere. It is expected that this will vary with the basin configuration and ocean physics, and we would like to extend our understanding of the marginal sea dynamics to be able to predict the heat flux lost to the atmosphere and, by implication, the heat flux across the sill into the marginal sea. The present study uses a similar approach to these previous studies, but now includes a wind-driven circulation and determines the meridional heat flux as part of the solution. It will be shown that all relevant quantities, such as density of the convective water mass, exchange rate between the marginal sea and the open ocean, and the meridional overturning circulation, depend crucially on eddy fluxes within the marginal sea and are different from the cases with a specified heat flux.

\section{An eddy-resolving model ocean with downwelling}

The problem of interest is introduced by consideration of a wind- and buoyancy-forced eddy-resolving ocean general circulation model. The model domain is idealized, allowing for straightforward parameter variations and comparison with theoretical estimates also derived. A central case is described in most detail, while many other calculations are carried out in a similar configuration with key parameters varied. Each of these calculations is similar in character to the central calculation, so only diagnosed quantities of interest from these additional calculations are presented and compared with the predictions from the theory.

The numerical model used in this study is the Massachusetts Institute of Technology (MIT) general circulation model (Marshall et al. 1997), which solves the hydrostatic, primitive equations on a uniform Cartesian, staggered $\mathrm{C}$ grid with level vertical coordinates. The model domain consists of an elongated basin $L_{y}=$ $2000 \mathrm{~km}$ in meridional extent and $L_{x}=1000 \mathrm{~km}$ in zonal extent that is subject to wind forcing and cooling at

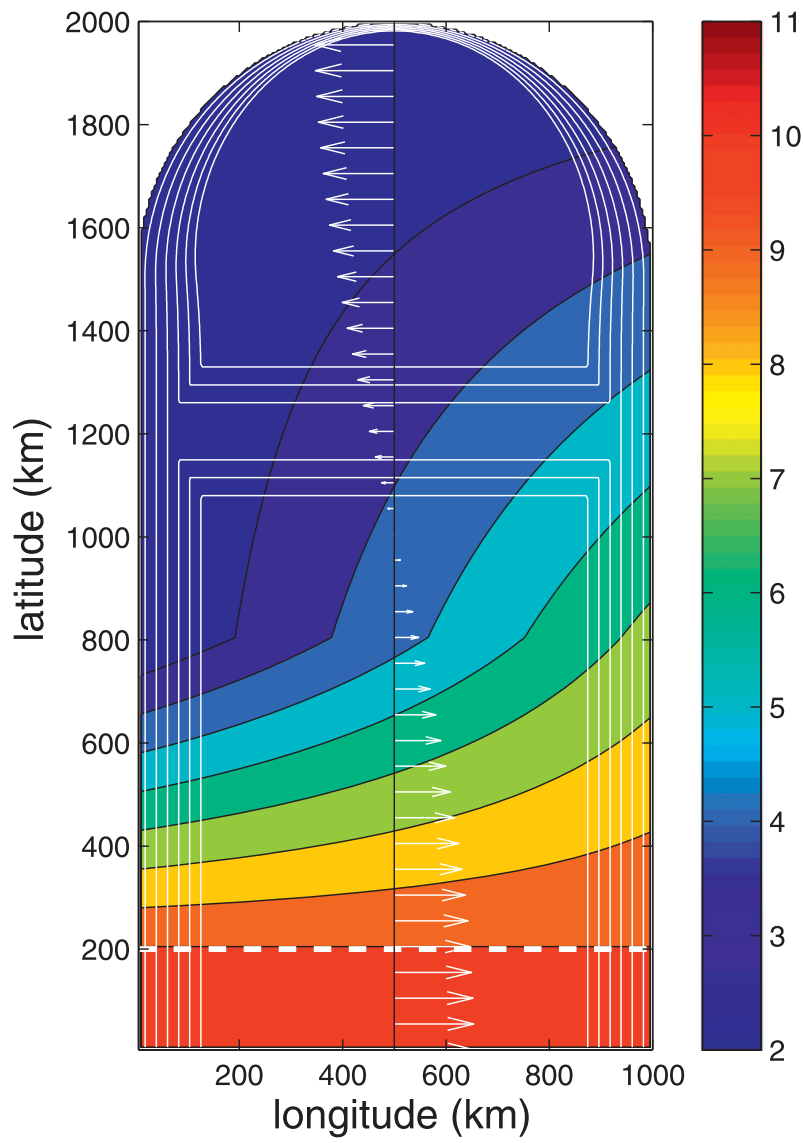

FIG. 1. Model domain, bottom topography [white contours, contour interval (c.i.) $=300 \mathrm{~m}]$. and atmospheric temperature toward which the model sea surface temperature is restored (colors). Temperature is restored toward a uniform stratification in the region south of the thick dashed white line at $200 \mathrm{~km}$.

the surface (Fig. 1). The domain has topography along the perimeter that slopes linearly from $50 \mathrm{~m}$ down to the bottom depth of $2000 \mathrm{~m}$ with a horizontal scale that varies from $140 \mathrm{~km}$ over most of the basin to $20 \mathrm{~km}$ along the northern boundary. The region of steep topography along the northern basin is included to approximately represent the steep topography along the Lofoten Basin, where the boundary current is observed to shed warm eddies into the basin interior (Poulain et al. 1996; Spall 2010a,b), although the fundamental results are not sensitive to this detail. Most calculations also have a sill located at $1200-\mathrm{km}$ latitude. The depth of the sill will be varied, the depth in Fig. 1 is $1000 \mathrm{~m}$. The Coriolis parameter varies linearly with latitude as $f=f_{0}+\beta y$, where $f_{0}=1.2 \times 10^{-4} \mathrm{~s}^{-1}$ and $\beta=2 \times 10^{-11} \mathrm{~m}^{-1} \mathrm{~s}^{-1}$. The horizontal resolution is $5 \mathrm{~km}$ and there are 20 levels in the vertical, varying from $25 \mathrm{~m}$ over the upper $250 \mathrm{~m}$ to $250 \mathrm{~m}$ over the deepest $1250 \mathrm{~m}$. Although the configuration is very idealized, and clearly not intended to 
represent any ocean basin in particular, the motivation for this study is the water mass transformation and circulation that takes place in the subpolar North Atlantic Ocean and Nordic Seas. The key aspects of the configuration are sloping topography around the perimeter of the basin, a sill, variable heat loss in the marginal sea, wind forcing, and eddy-resolving dynamics.

The model is forced with a wind stress, which may be written in general form as

$$
\boldsymbol{\tau}(x, y)=\mathbf{i} \tau_{0}^{x} \cos \left(\pi y / L_{y}\right)+\mathbf{j} \tau_{0}^{y} \cos \left(\pi x / L_{x}\right) .
$$

The central calculation is forced with a zonal wind stress only $\left(\tau_{0}^{x}=0.15 \mathrm{~N} \mathrm{~m}^{-2}, \tau_{0}^{y}=0\right)$. The meridional distribution is indicated on Fig. 1 at the midpoint of the basin. This gives a maximum Ekman upwelling velocity of approximately $15 \mathrm{~cm}^{-1}$ day $^{-1}$, which is close to the climatological mean in the interior of the Nordic Seas and in the eastern North Atlantic south of the sill (Nost and Isachsen 2003; Furevik and Nilsen 2005). The real wind stress is enhanced near the eastern and western boundaries, particularly in winter, but the zonally uniform, steady winds applied here are of strength intermediate to that found in the basin interior and near the boundaries, and suitable for the steady circulation and heat transport. Meridional wind stress will be applied in section $3 \mathrm{e}$.

The surface heat flux in the model $\left(Q^{*}\right)$ is calculated by restoring the upper-level temperature $T$ toward a prescribed atmospheric temperature $T_{A}$. The restoring strength $\Gamma=20 \mathrm{~W} \mathrm{~m}^{-2} \mathrm{C}^{-1}$ for the central calculation, although this will be varied:

$$
Q^{*}=\left(T-T_{A}\right) \Gamma .
$$

The atmospheric temperature is warmer in the south and cooler in the north and northwest, approximating the influence of cold air outbreaks originating in the subpolar North Atlantic and Canada (Fig. 1), although the general results only require cooling at high latitudes and heating at low latitudes. The stratification in the southernmost $200 \mathrm{~km}$ is also restored toward a temperature profile with uniform vertical stratification of $N^{2}=\left(\mathrm{g} / \rho_{0}\right) \partial \rho / \partial \mathrm{z}=2 \times 10^{-6} \mathrm{~s}^{-2}$ and an upper-level temperature of $10^{\circ} \mathrm{C}$ with a time scale of 20 days (south of the bold dashed line in Fig. 1). This gives a first baroclinic deformation radius, based on the full ocean depth, of $L_{d}=N H / f_{0}=20 \mathrm{~km}$. This restoring is intended to represent the thermodynamic processes that maintain the stratification at low latitudes. The advantage of this approach is that the model can attain a statistical equilibrium over the relatively short time scale set by advective processes in the cooling regions instead of being constrained by the slow processes that are responsible for maintaining the low-latitude stratification. This likely involves both diapycnal diffusion and advection from the Southern Ocean, both of which would require a long time to achieve equilibrium. This allows for efficient execution of large numbers of eddy-resolving model calculations. One drawback of the restoring approach is that there is no feedback allowed between the processes that determine the properties of the water mass transformation at high latitudes and the properties of the waters advected northward from low latitudes.

The model incorporates second-order vertical viscosity and diffusivity with coefficients $10^{-5} \mathrm{~m}^{2} \mathrm{~s}^{-1}$. The vertical diffusion is increased to $1000 \mathrm{~m}^{2} \mathrm{~s}^{-1}$ for statically unstable conditions in order to represent vertical convection. Horizontal viscosity is parameterized as a second-order operator with the coefficient $A_{h}$, determined by a Smagorinsky (1963) closure as $A_{h}=\left(\nu_{s} / \pi\right)^{2} \Delta^{2}$ $\left[\left(u_{x}-v_{y}\right)^{2}+\left(u_{y}+v_{x}\right)^{2}\right]^{1 / 2}$, where $\nu_{s}=2.5$ is a nondimensional coefficient, $\Delta$ is the grid spacing, and $u$ and $v$ are the horizontal velocities (subscripts indicate partial differentiation). Temperature is advected with a thirdorder direct space-time flux-limiting scheme (the MITgcm tracer advection option 33; see online at http://mitgcm. org). There is no explicit horizontal diffusion of temperature. Density is linearly related to temperature with a thermal expansion coefficient of $-0.2 \mathrm{~K} \mathrm{~g} \mathrm{~m}^{-3}{ }^{\circ} \mathrm{C}^{-1}$.

The model is started at a state of rest with an initial stratification of $N^{2}=2 \times 10^{-6} \mathrm{~s}^{-2}$ and upper-level temperature of $10^{\circ} \mathrm{C}$. The model is run for a period of 30 years, which is sufficient to achieve a statistical steady state (as indicated by basin-integrated available potential energy or kinetic energy, and also the quantities diagnosed below). The primary differences between this model configuration and that used by Spall (2004) and Iovino et al. (2008) is that the buoyancy forcing is parameterized by restoring the model upper-level temperature toward an atmospheric temperature, the inclusion of wind forcing, and a large southern basin. The change in buoyancy forcing is important because the heat flux into the marginal sea was specified in the previous calculations while it is an unknown in the present calculations. One of the primary objectives of this study is to better understand what controls the heat flux northward across the sill, so this difference in forcing is essential to the problem. The addition of wind forcing and a larger southern basin allow for a more complete representation of the circulation outside the marginal sea and for the possibility of wind-driven exchange across the sill.

Although clearly very idealized compared to the real ocean, the model represents several key aspects of the observed circulation in the northern North Atlantic Ocean and Nordic Seas (Orvik and Niiler 2002; Jakobsen 


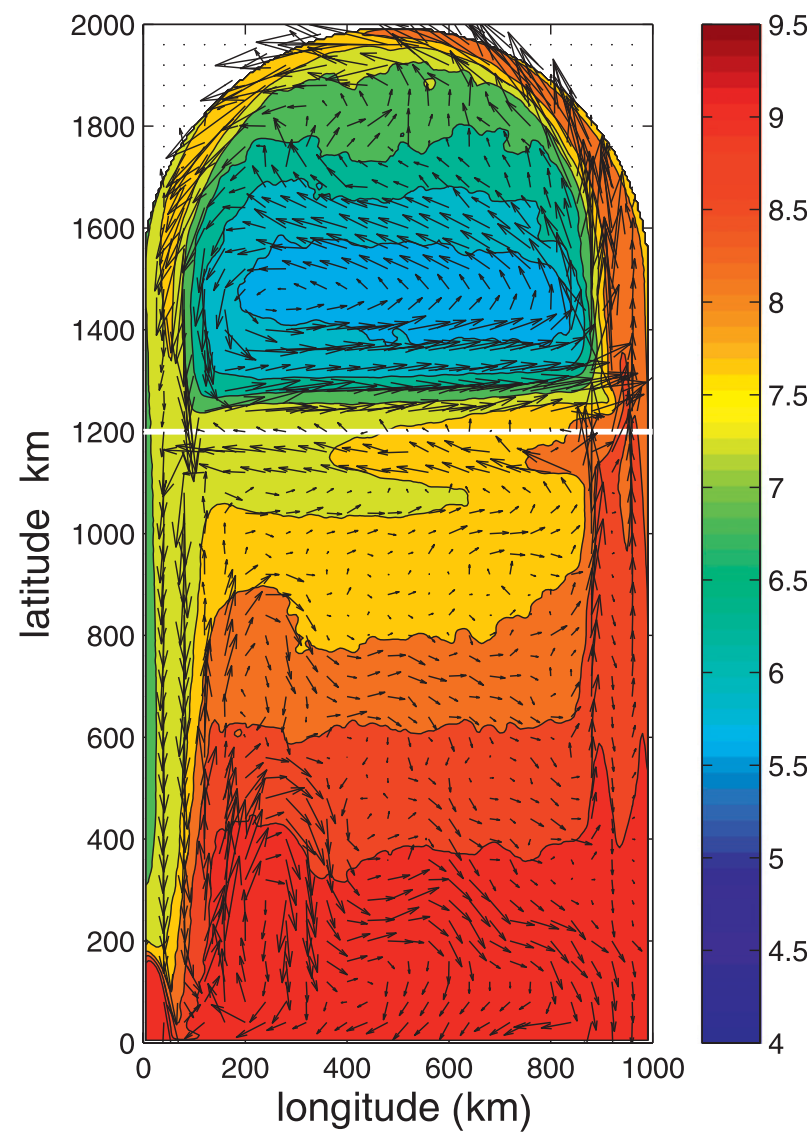

FIG. 2. Average over the final 5 years of integration of temperature and horizontal velocity (every eighth grid vector) at the upper level. The crest of the sill is indicated by the white line at $1200-\mathrm{km}$ latitude.

et al. 2003). The mean basin-scale circulation is cyclonic in both the central and northern basins (Fig. 2). Warm water is advected northward along the western boundary at low latitudes, crosses the basin in the middle of the southern basin, and continues northward along the eastern boundary. Upon reaching the sill, the warm current splits into two branches, one flowing to the west along the southern flank of the sill and the other continuing toward the north into the marginal sea. A similar branching south of the sill is seen in observations (Orvik and Niiler 2002; Brambilla and Talley 2008). The temperature decreases monotonically along both pathways as a result of heat loss to the atmosphere and, it will be shown, lateral eddy fluxes. The coldest waters in the model are found in the center of the marginal sea. The water flowing southward along the western boundary of the marginal sea is colder than the northward flowing water along the eastern boundary, but is not as cold as the convective waters in the interior of the marginal sea.
The presence of mesoscale eddies, and their source region, are indicated by a synoptic view of the sea surface temperature in the marginal sea (Fig. 3). The same basic features found in the mean hydrography and circulation are indicated here as well, but the strong eddy temperature flux from the boundary into the interior of the marginal sea is now evident. The eddies originate from the warm cyclonic boundary current, primarily separating from the boundary in the region of steep topography in the north. Similar eddy shedding is seen from steep topography in the Lofoten Basin (Poulain et al. 1996; Spall 2010a). There is also some time dependence over the sill and in the inflowing and outflowing boundary currents.

A sense of the baroclinic time-mean circulation and hydrography near the ridge and within the marginal sea is indicated by a meridional section at $x=500 \mathrm{~km}$ (Fig. 4). There is a baroclinic front over the sill, with warm water to the south and weakly stratified cold water to the north. The flow over the sill is strongly baroclinic and primarly along the topography, toward the west on the southern flank and toward the east along the northern flank of the topography. The warm cyclonic boundary current is evident in both temperature and velocity along the northern boundary. Note that the warm water is confined to depths less than the sill depth (Iovino et al. 2008; Spall 2010a). The flow in these frontal regions is stratified, indicating that mean lateral advection is balancing surface heat loss to limit the depth of convection. The stratification is weaker both to the south of the sill and within the marginal sea. Deep convection penetrates to the bottom in the southern part of the marginal sea, while eddy fluxes from the boundary current restratify from the north. The deformation radius, calculated as $L_{d}=f^{-1} \int N d z$, is $O(15-20 \mathrm{~km})$ in the frontal regions but drops to approximately $5 \mathrm{~km}$ in the weakly stratified interior. There is also a nearly barotropic mean circulation in the interior, cyclonic over the central and southern basin and weakly anticyclonic in the north (see also Fig. 2).

A zonal section along the crest of the sill shows that the primary mean exchanges between the subpolar gyre and the marginal sea take place near the eastern and western boundaries (Fig. 5). The inflowing boundary current is warm at all depths and the velocity increases monotonically toward the surface. The outflowing boundary current shows two velocity maxima, one in the dense outflow at the bottom and the other in the weakly stratified, intermediate density in the upper $500 \mathrm{~m}$. These are the model analogs of the Denmark Strait overflow and the East Greenland Current.

The heat loss from the ocean to the atmosphere in the marginal sea is balance by northward advection of 


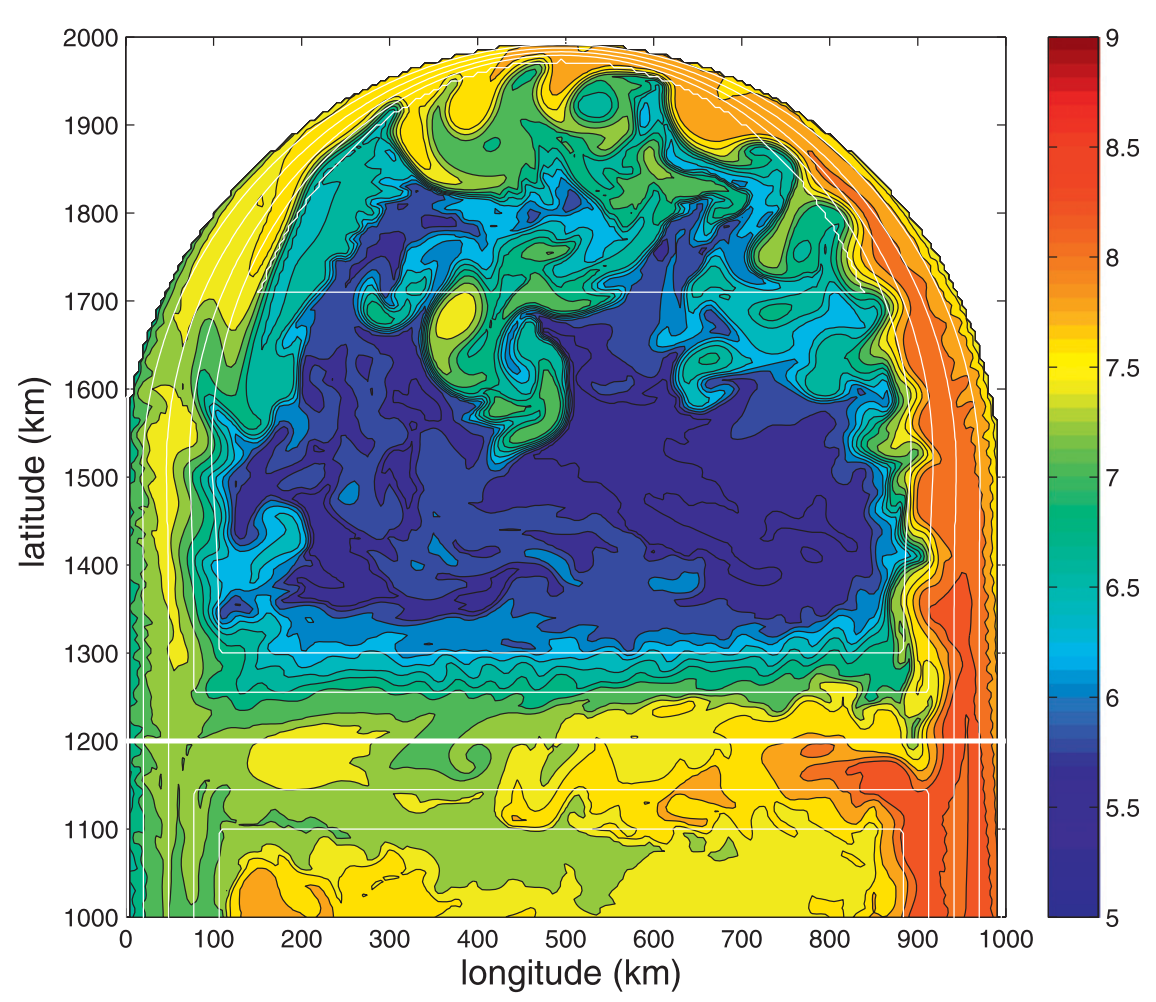

FIG. 3. Snapshot of the sea surface temperature $\left(\mathrm{c} . \mathrm{i} .=0.25^{\circ} \mathrm{C}\right)$ near the end of the calculation. The topography is indicated by the thin white lines $($ c.i. $=400 \mathrm{~m})$, and the sill location is indicated by the thick white line at $1200-\mathrm{km}$ latitude.

warm water across the sill. The zonally integrated meridional heat transport is shown in Fig. 6 as a function of latitude. The total heat transport is decomposed into contributions due to the mean and time-dependent (eddy) motions. The majority of the heat transport into the marginal sea (across the sill at 1200-km latitude) is carried by the mean flow, as reflected in Fig. 5 by the difference in temperature between the inflowing and outflowing boundary currents. Very near the sill there is a significant contribution from eddies, which is compensated by a reduction in the mean so the total meridional heat transport varies slowly across the sill. The inflowing boundary current becomes time dependent as it crosses the sill near the eastern boundary, resulting is some exchange between mean and time-dependent contributions, but just north of the sill the mean flow once again dominates. Farther to the north, the mean heat transport is northward and the eddy heat transport southward. This highlights the different roles of the boundary current and the eddy fluxes in transporting heat within the marginal sea. The boundary current transports warm water northward, giving rise to a positive heat flux. The eddies are formed at the steep topography in the northern part of the basin and carry the heat southward into the interior (Fig. 3), giving rise to a southward heat flux.

\section{Sensitivity to environmental parameters}

These model results can be used as a general guideline to construct a simple, conceptual model of the circulation and exchange between the marginal sea and the southern basin, which can then be used to understand what controls the basic characteristics of the exchange (e.g., heat flux, convective water density, overturning circulation). Following Spall (2004), it is assumed that the water mass characteristics of the marginal sea can be represented by three water masses: the inflowing water (temperature $T_{1}$ ), the outflowing water (temperature $\left.T_{\text {out }}\right)$, and a convective water mass in the interior of the marginal sea (temperature $T_{0}$ ). It is assumed that the exchange over the sill is carried in a mean cyclonic boundary current that follows the topographic contours from the open ocean into the marginal sea along the eastern boundary and back to the open ocean along the western boundary. The conceptual model will require that the boundary current be in thermal wind balance with the lateral density gradient, that the net mass flux across the sill is zero, and that the heat loss to the atmosphere is balanced by heat advection in the ocean. While clearly an oversimplification, comparison with a series of full numerical model calculations demonstrate 

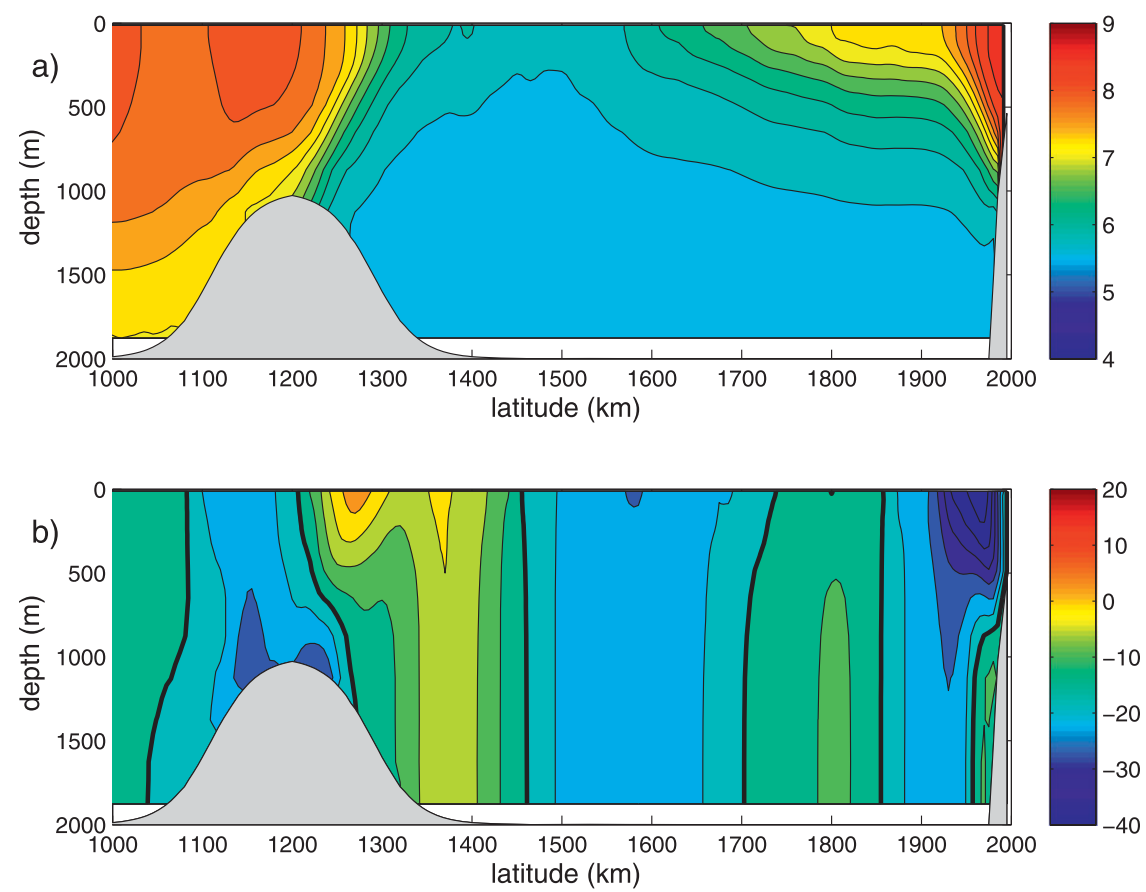

FIG. 4. Meridional section of the mean (a) temperature $\left(\mathrm{c} . i .=0.25^{\circ} \mathrm{C}\right)$ and $(\mathrm{b})$ zonal velocity (c.i. $=5 \mathrm{~cm} \mathrm{~s}^{-1}$, thick black line is the zero contour) at $x=500 \mathrm{~km}$.

the utility of this approach. Note that, at this point, no assumptions have been made about the relative importance of wind and buoyacy forcing in driving the mean circulation.

\section{a. Temperature of the convective water mass}

The density of the convective water mass formed in the interior of the marginal sea can be determined by
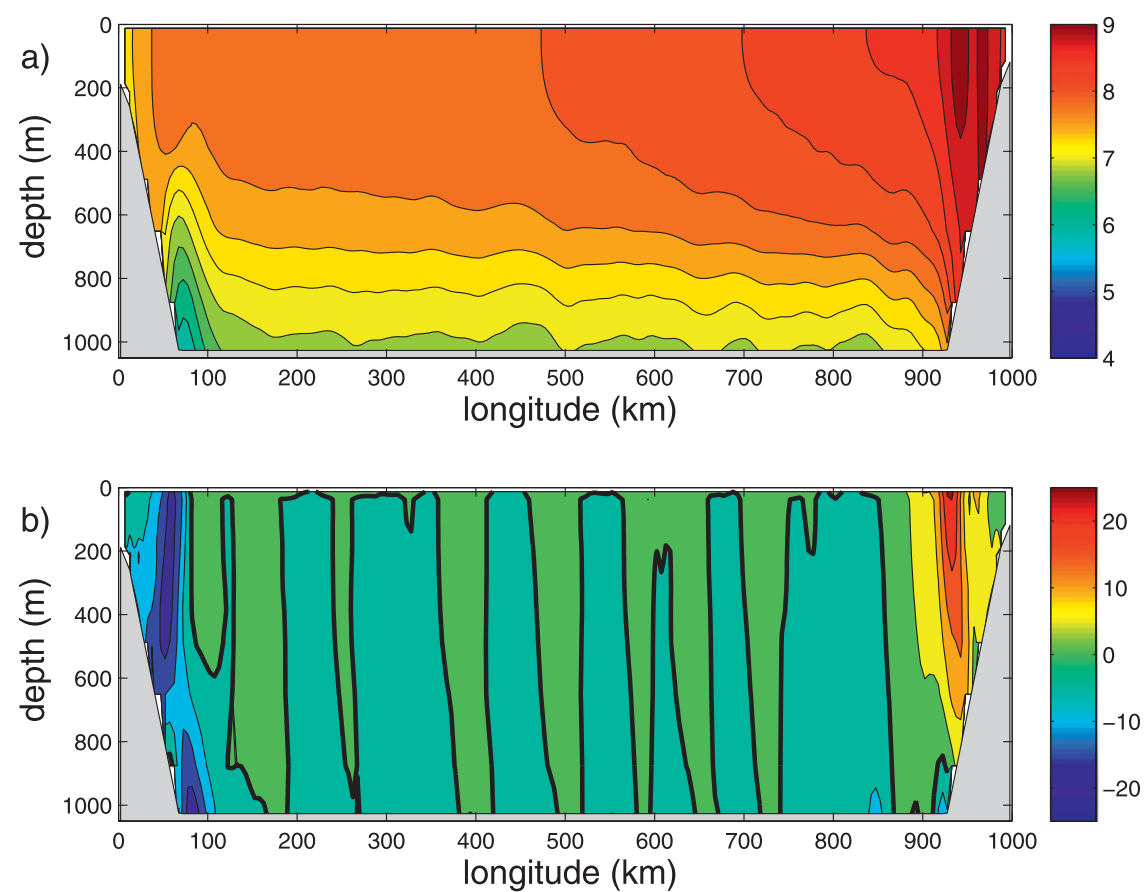

FIG. 5. Zonal section of the mean (a) temperature $\left(\right.$ c.i. $\left.=0.25^{\circ} \mathrm{C}\right)$ and $(\mathrm{b})$ zonal velocity (c.i. $=5 \mathrm{~cm} \mathrm{~s}^{-1}$, thick black line is the zero contour) at the sill $(y=1200 \mathrm{~km})$. 


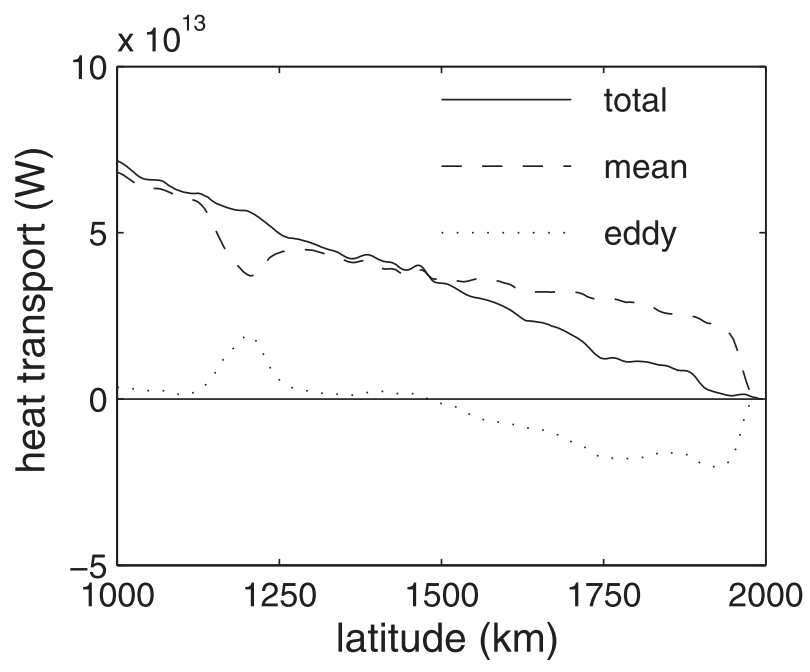

FIG. 6. Meridional heat transport: total (solid), mean (dashed), and eddy (dotted) contributions.

recognizing that the heat loss in the interior of the marginal sea is balanced by lateral eddy fluxes originating in the boundary current. The mean flow in the interior of the marginal sea is along closed topographic contours, and thus does not contribute directly to the heat transport into the interior of the marginal sea (Spall 2004; Iovino et al. 2008). When started from rest, the density of the convective waters increases until the baroclinic shear between the boundary current and the interior is sufficiently large that the boundary current sheds enough warm eddies into the basin interior to balance heat loss to the atmosphere (Spall 2004). This is a key step in constraining the solution because the strength of the boundary current is determined by the heat loss in the basin interior and the stability characteristics of the boundary current. For the present case, where the air-sea heat flux is calculated by a relaxation of the sea surface temperature in the basin interior $\left(T_{0}\right)$ to an atmospheric temperature $\left(T_{A}\right)$ with a constant of proportionality $\Gamma$, this balance is

$$
P H \overline{u^{\prime} T^{\prime}}=\frac{A \Gamma\left(T_{0}-T_{A}\right)}{\rho_{0} C_{p}},
$$

where the overbar denotes a time average, primes indicate perturbations from the time mean, $u^{\prime}$ is the velocity component directed into the basin interior, $P$ is the perimeter of the interior of the marginal sea (where the topography is flat or the topographic contours are closed), $A$ is the surface area of the interior of the marginal sea, $H$ is the sill depth, $\rho_{0}$ is a representative ocean density, and $C_{p}$ is the specific heat of seawater: $T_{A}=2.8^{\circ} \mathrm{C}$ is the spatial average of the restoring temperature over the marginal sea.
The eddy heat flux is parameterized as being proportional to the baroclinic velocity in the inflowing boundary current $V_{1}$ and the temperature gradient between the boundary current and the basin interior (Visbeck et al. 1996; Spall 2004):

$$
\overline{u^{\prime} T^{\prime}}=c V_{1}\left(T_{1}-T_{0}\right)
$$

For simplicity, it is assumed that the temperature of the boundary current is the same as the temperature of the ocean to the south of the sill along the eastern boundary, denoted as $T_{1}$. The coefficient $c$ depends on the bottom slope approximately as $c=0.025 e^{2 \delta}$, as derived from linear baroclinic stability theory in Spall (2004). Analysis of the energetics indicates that the eddies are formed from baroclinic instability of the boundary current (Spall 2010a,b). The nondimensional parameter $\delta$ is the ratio of the bottom slope to the mean isopycnal slope in the boundary current. It is found to be between -0.5 and -1 for all calculations presented here. The general results are not overly sensitive to its exact value, so for simplicity it is taken to be -0.7 for all cases, giving $c=0.006$. Isachsen (2011) tested the linear stability theory used by Spall (2004) over a wide range of bottom slopes and nonlinearity and found generally close agreement between the theory and a nonlinear model for $-1<\delta<0$.

The depth-averaged baroclinic velocity in the boundary current is assumed to be in thermal wind balance, so it also depends linearly on the temperature difference between the boundary current and the interior:

$$
V_{1}=\frac{\alpha g H\left(T_{1}-T_{0}\right)}{2 \rho_{0} f_{0} L},
$$

where $g$ is the gravitational acceleration and $\alpha$ is the thermal expansion coefficient. Here, $L$ is the width of the sloping topography over which the boundary current lies, which is assumed to be given by those topographic contours that connect from the open ocean into the marginal sea (Iovino et al. 2008) as

$$
L=H / s,
$$

where $s=0.02$ is the average bottom slope around the perimeter of the marginal sea. For simplicity, it is assumed that the temperature of the boundary current is $T_{1}$ and constant around the perimeter of the basin. In reality, as heat is lost to the atmosphere, $T_{1}$ and $V_{1}$ decrease around the perimeter of the basin. Such spatial dependence would be difficult to represent in the following analytical solution, although it is fairly straightforward to consider its impact on the heat budget of the marginal sea, as discussed in section $3 \mathrm{~b}$. 
Using these conditions, the heat balance (3) may be written as

$$
\frac{\alpha g c P H^{2}\left(T_{1}-T_{0}\right)^{2}}{2 \rho_{0} f_{0} L}=\frac{A \Gamma\left(T_{0}-T_{A}\right)}{\rho_{0} C_{p}} .
$$

This expression can be used to derive a quadratic equation for $T_{0}$, which is readily solved for the temperature of the water formed in the interior of the basin relative to that of the inflowing water:

$$
T_{1}-T_{0}=\frac{\mu}{\epsilon}\left[(1+2 \epsilon / \mu)^{1 / 2}-1\right]\left(T_{1}-T_{A}\right) .
$$

The nondimensional $\epsilon=c P / L$ is the ratio of the heat fluxed into the basin interior by eddies compared to that advected into the basin in the inflowing boundary current (relative to $T_{0}$; Spall 2004). The value of $\epsilon$ is very small for stable boundary currents and increases to 1 for boundary currents that are sufficiently unstable that they lose all their heat to the interior of the basin before it is carried all the way around the marginal sea. The parameter $\mu$ is also nondimensional, defined as

$$
\mu=\frac{A \Gamma f_{0}}{\alpha g C_{p} H^{2}\left(T_{1}-T_{A}\right)} .
$$

For the calculation shown in Fig. 2, the average inflowing temperature is $T_{1}=8.87^{\circ} \mathrm{C}$ and the average temperature in the basin interior is $T_{0}=6.54^{\circ} \mathrm{C}$, giving $T_{1}-T_{0}=2.33^{\circ} \mathrm{C}$. The theoretical prediction given by (8) is $2.72^{\circ} \mathrm{C}$. While this comparison is reasonably close, a more stringent test of the theory is achieved by comparing it with model results over a wide range of parameter space. Thirteen different model calculations have been carried out in which the sill depth, restoring constant $\Gamma$, and Coriolis parameter $f_{0}$ have been varied (Table 1 ). The temperature of the interior convective water mass found in the model, relative to the inflowing temperature, is compared to that predicted by (8) in Fig. 7a (the asterisk is the central case in Fig. 2). In general, the comparison is quite good, with the theory correctly predicting the sensitivity of the convective water mass to each of the parameters varied. The temperature anomaly of the product water varies from less than $1^{\circ}$ to nearly $6^{\circ} \mathrm{C}$. In each of these cases, the atmospheric temperature is the same, so differences in the density of the convective water are a result of changes in the parameters that define the marginal sea, not those external to the marginal sea.

The temperature of the convective water mass, when scaled by the temperature scale inherent to the forcing, $T_{1}-T_{A}$, depends only on the nondimensional ratio of
TABLE 1. Summary of standard wind-forced model runs with key parameters: sill depth $H(\mathrm{~m})$, Coriolis parameter $f_{0}\left(10^{-4} \mathrm{~s}^{-1}\right)$, relaxation constant $\Gamma\left(\mathrm{W} \mathrm{m}^{-2} \mathrm{C}^{-1}\right)$, and ratio $\mu / \epsilon$. The model diagnosed quantities: temperature of the convective water mass $\left(T_{0},{ }^{\circ} \mathrm{C}\right)$, temperature of the outflowing water $\left(T_{\text {out }},{ }^{\circ} \mathrm{C}\right)$, the meridional heat transport at the sill $\left(10^{13} \mathrm{~W} \mathrm{~m}^{-2}\right)$, and the maximum meridional overturning strength at the sill $W\left(10^{6} \mathrm{~m}^{3} \mathrm{~s}^{-1}\right)$.

\begin{tabular}{rrrrlccccl}
\hline \hline & & & & & \multicolumn{5}{c}{ Heat } \\
Run & \multicolumn{1}{c}{$H$} & $f_{0}$ & $\Gamma$ & $\mu / \epsilon$ & $T_{0}$ & $T_{\text {out }}$ & flux & $W$ & Symbol \\
\hline 1 & 1000 & 1.4 & 20 & 0.15 & 6.54 & 7.80 & 5.66 & 2.32 & Asterisk \\
2 & 2000 & 1.4 & 20 & 0.09 & 7.51 & 7.92 & 6.49 & 2.92 & Square \\
3 & 600 & 1.4 & 20 & 0.36 & 5.17 & 7.04 & 3.81 & 1.47 & Square \\
4 & 300 & 1.4 & 20 & 1.4 & 4.30 & 6.56 & 2.69 & 0.79 & Square \\
5 & 2000 & 1.4 & 7 & 0.03 & 8.09 & 8.26 & 2.40 & 1.81 & Circle \\
6 & 2000 & 0.5 & 7 & 0.01 & 8.46 & 8.48 & 2.51 & 2.92 & Circle \\
7 & 2000 & 0.25 & 7 & 0.005 & 8.65 & 8.55 & 2.85 & 4.12 & Circle \\
8 & 1000 & 1.4 & 7 & 0.05 & 7.38 & 8.21 & 1.97 & 1.49 & Triangle \\
9 & 1000 & 1.4 & 60 & 0.52 & 5.40 & 6.09 & 12.6 & 3.68 & Triangle \\
10 & 1000 & 1.4 & 30 & 0.25 & 6.16 & 6.92 & 7.96 & 2.63 & Triangle \\
11 & 300 & 1.4 & 60 & 4.8 & 3.10 & 5.07 & 3.68 & 1.07 & Star \\
12 & 200 & 1.4 & 120 & 25 & 2.85 & 4.89 & 2.72 & 0.65 & Star \\
13 & 200 & 2.8 & 120 & 53 & 2.82 & 4.72 & 1.38 & 0.25 & Star \\
\hline
\end{tabular}

$\mu / \epsilon$. This is evident from a comparison of the scaled temperature difference $\left(T_{1}-T_{0}\right) /\left(T_{1}-T_{A}\right)$ found in the model with the theory (8) as a function of $\mu / \epsilon$ in Fig. $7 \mathrm{~b}$. For $\mu / \epsilon \ll 1$, the temperature of the interior water mass approaches that of the inflowing water. In this regime, eddy fluxes are sufficiently strong compared to the atmospheric cooling that the interior of the basin is relatively warm. For $\mu / \epsilon \gg 1$, the temperature of the convective water mass approaches the atmospheric temperature $T_{A}$. In this limit, the eddies are relatively inefficient in transporting heat from the boundary into the interior, the atmospheric influence dominates, and the heat loss from the marginal sea to the atmosphere goes to zero. This behavior was not possible in the previous configurations by Spall (2004) and Iovino et al. (2008) and indicates that the heat loss to the atmosphere, and thus heat flux into the marginal sea, can be strongly influenced by eddy fluxes. This will be further explored in section $3 \mathrm{~b}$.

Some physical insight into the nondimensional $\mu / \epsilon$ may be obtained if it is written as the product of three terms:

$$
\frac{\mu}{\epsilon}=\frac{\rho_{0} f_{0}}{\alpha g H^{2}\left(T_{1}-T_{A}\right)} \frac{1}{\epsilon} \frac{A \Gamma}{\rho_{0} C_{p}} .
$$

The first term on the right-hand side of (10) is proportional to one over the transport that would be carried in the boundary current if the interior of the marginal sea was at temperature $T_{A}$. The $\epsilon^{-1}$ term projects this boundary current transport into an effective transport into the interior of the marginal sea due to eddies. The 

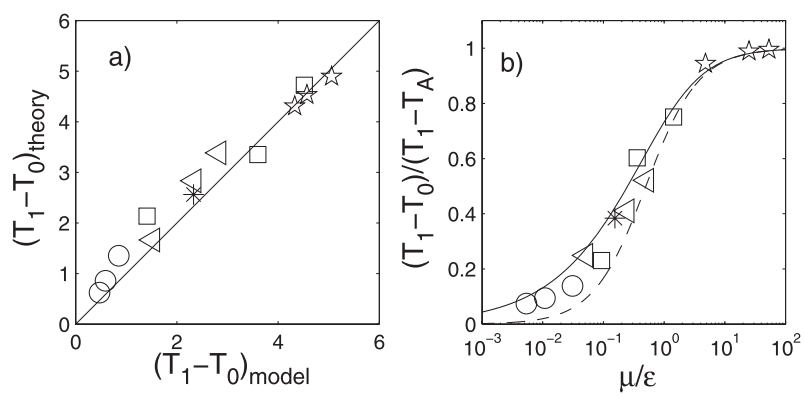

FIG. 7. (a) Comparison of the diagnosed difference between the inflowing temperature $T_{1}$ and the temperature in the marginal sea interior $T_{0}$ from the model with that predicted by $(8)\left({ }^{\circ} \mathrm{C}\right)$. The central case is indicated by the asterisk; the other symbols represent variations in the model parameters, as summarized in Table 1. (b) The nondimensional temperature difference diagnosed from the model (symbols), from the theory (8) (solid line), and approximate theory (12) as a function of the nondimensional parameters $\mu / \epsilon$.

final term is an effective "transport" from the marginal sea into the atmosphere based on the strength of the air-sea exchange coefficient $\Gamma\left(\mathrm{m}^{3} \mathrm{~s}^{-1}\right)$. The combination $\mu / \epsilon$ measures the relative transport into the atmosphere compared to that into the marginal sea from the open ocean (via eddy fluxes from the boundary). Small values of $\mu / \epsilon$ indicate dominance from lateral advection in the ocean while large values indicate a strong atmospheric influence. Once these asymptotic limits are reached, further increases or decreases in the ratio $\mu / \epsilon$ have no effect on the properties of the convective water mass.

An approximate solution for $T_{1}-T_{0}$ can be obtained if the heat transport into the atmosphere (given by the above "transport" times $T_{0}-T_{A}$ ) is balanced by the heat transport into the marginal sea by the eddy fluxes (given by the above transport times $T_{1}-T_{0}$ ):

$$
\begin{aligned}
& \frac{2 \rho_{0} f_{0}}{\alpha g H^{2}\left(T_{1}-T_{A}\right)} \frac{1}{\epsilon} \frac{1}{\left(T_{1}-T_{0}\right)} \frac{A \Gamma}{\rho_{0} C_{p}}\left(T_{0}-T_{A}\right) \\
& =\frac{2 \mu}{\epsilon} \frac{\left(T_{0}-T_{A}\right)}{\left(T_{1}-T_{0}\right)}=1 .
\end{aligned}
$$

This may be solved for $T_{1}-T_{0}$ as

$$
\frac{T_{1}-T_{0}}{T_{1}-T_{A}}=\frac{2 \mu / \epsilon}{1+2 \mu / \epsilon} .
$$

This approximate solution is indicated in Fig. $7 b$ by the dashed line. It generally reproduces the full analytic solution, and the model results, but underpredicts the temperature anomaly for small $\mu / \epsilon$. This is because the approximate solution assumes the interior temperature is at $T_{A}$ when calculating the baroclinic shear in the boundary current, while for small $\mu / \epsilon$ the interior temperature approaches $T_{1}$. As a result, the approximate solution overestimates the heat flux from the boundary current into the interior, and thus also underestimates the interior temperature anomaly. Nonetheless, the general agreement is good and lends support to the simple physical interpretation of the ratio $\mu / \epsilon$.

\section{b. Meridional heat flux across the sill}

Once the temperature of the convective water mass is known, it is straightforward to estimate the heat loss to the atmosphere, one of the primary quantities of interest in this study. In the steady state, this is also the flux that must be carried by the ocean across the sill into the marginal sea:

$$
\begin{aligned}
Q^{*} & =A\left(T_{0}-T_{A}\right) \Gamma+P_{e} L\left(T_{1}-T_{A}\right) \Gamma \\
& =A \Gamma\left[\left(1+P_{e} L / A\right)\left(T_{1}-T_{A}\right)-\left(T_{1}-T_{0}\right)\right] .
\end{aligned}
$$

The term $A\left(T_{0}-T_{A}\right) \Gamma$ represents the heat loss to the atmosphere in the interior of the basin and the term $P_{e} L\left(T_{1}-T_{A}\right) \Gamma$ represents the heat loss to the atmosphere directly from the boundary current. The first term arises solely due to the eddy fluxes, while the second term is due only to mean advection in the boundary current.

For simplicity, it has so far been assumed that the temperature in the boundary current is $T_{1}$ and uniform around the basin. This will produce a higher estimate of the heat flux than would be found if the temperature of the boundary current were to decay as it loses heat (as actually occurs), but in most cases this effect is small. However, if the heat loss from the boundary current is sufficiently strong that it loses all of its temperature anomaly before it encircles the basin, then the area of heat loss in the boundary current will be less than $P L$. This effect is taken into account by using an effective perimeter given by

$$
P_{e}=\min \left(P, V_{1} \rho_{0} C_{p} h_{1} / \Gamma\right),
$$

where $V_{1}$ is the velocity of the inflowing boundary current [calculated using the theory (8)] and $h_{1}$ is the thickness of the upper layer. The quantity $\rho_{0} C_{p} h_{1} / \Gamma$ is the time scale of relaxation of SST to the atmospheric temperature. This distinction between $P$ and $P_{e}$ is only important for those few calculations that have a very strong restoring time scale of 20 days or less so that $T_{0} \rightarrow T_{A},\left(\Gamma \geq 60 \mathrm{~W} \mathrm{~m}^{-2} \mathrm{C}^{-1}\right.$, Table 1). Direct heat loss from the boundary current would also become important if $P_{e} L / A=O(1)$ (not considered here).

A comparison of the total heat flux across the sill from the series of model calculations with that predicted by 

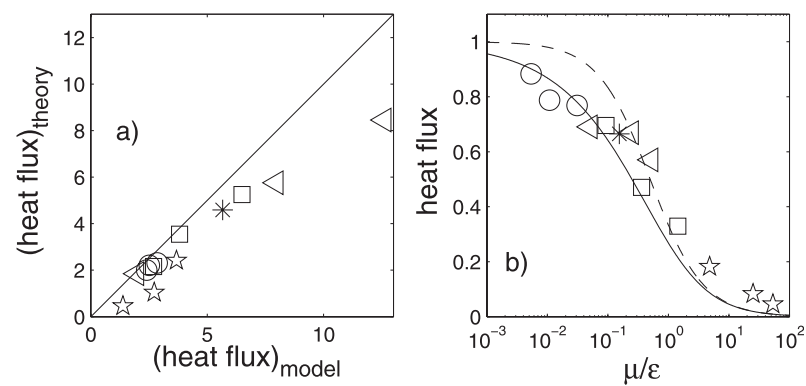

FIG. 8. (a) Comparison of the meridional heat flux across the sill $\left(10^{13} \mathrm{~W}\right)$ diagnosed from the model and that predicted by (13). (b) Nondimensional meridional heat flux diagnosed from the model runs, from the theory (15) (solid line) and making use of the approximate theory (12) (dashed line) as a function of the nondimensional parameters $\mu / \epsilon$.

(13), using (8), is shown in Fig. 8a. Again the comparison is reasonably close, with the theory correctly predicting the sensitivity of the meridional heat flux to each of the parameters. The bias of the theory in underpredicting the heat flux into the marginal sea might be a result of the neglect of eddy fluxes directly across the sill in the theory. Although apparently only of secondary importance for the present configurations, it is possible that, for some configurations, eddy fluxes might become more important.

A measure of the efficiency of the oceanic heat transport may be attained by comparing the actual heat transport to the largest heat flux that could be supported by the system. For a heat exchange with the atmosphere that is parameterized by restoring the ocean SST to an atmospheric temperature with strength $\Gamma$, the largest possible heat flux would be found if the entire marginal sea were at the warmest temperature in the system, $T_{1}$. If (13) is scaled by this maximum heat flux, the nondimensional heat flux is

$$
\begin{aligned}
Q & =1-\left(1+P_{e} L / A\right)^{-1}\left(T_{1}-T_{0}\right) /\left(T_{1}-T_{A}\right) \\
& =1-\frac{\mu}{\epsilon}\left[(1+2 \epsilon / \mu)^{1 / 2}-1\right]\left(1+P_{e} L / A\right)^{-1} .
\end{aligned}
$$

With this expression, it is clear that the ocean transports the most heat flux possible when $\mu / \epsilon$ is small. This regime is dominated by lateral eddy heat fluxes from the boundary current, which makes it clear that lateral eddy fluxes within the marginal sea are very important for attaining meridional heat transport across the sill. This lateral transport by the eddies exposes more warm water to atmospheric cooling, thus increasing the heat loss to the atmosphere. This theoretical estimate is compared to the scaled heat transport in the model in Fig. $8 \mathrm{~b}$. The general transition from an effective ocean heat transport regime for $\mu / \epsilon \ll 1$ to an ineffective regime for $\mu / \epsilon \gg 1$ is also found in the model. The dashed line is the heat flux obtained from (15) using the approximate solution for $\left(T_{1}-T_{0}\right) /\left(T_{1}-T_{A}\right)$ from (12).

Two regimes similar to the limits predicted by (8) and (15) can be found in the Nordic Seas. In the Lofoten Basin (in the northeastern part of the Nordic Seas) warm, salty water of Atlantic origin floods the interior of the basin as a result of eddy formations from a region of steep topography along the eastern boundary (Poulain et al. 1996; Spall 2010a). This heat is lost to the atmosphere, resulting in moderately deep convection and the largest surface heat loss in the Nordic Seas (Isachsen et al. 2007). The Lofoten Basin corresponds to the eddydominated limit of small $\mu / \epsilon$. The Greenland Sea, in the western Nordic Seas, is much colder and experiences deeper convection during late winter, even though the surface buoyancy loss is much less than that found in the Lofoten Basin. This difference is explained by the lack of eddy shedding from the boundary current (no region of steep topography). The Greenland Sea corresponds to the limit of large $\mu / \epsilon$. The difference in $\mu / \epsilon$ comes from both a larger $T_{1}-T_{A}$ due to warm Atlantic water in the Norwegian Atlantic Current, and a larger $\epsilon$ due to the steep topography, than are found in the Greenland Sea. All other parameters in (10) are approximately the same in both basins.

\section{c. Temperature of the outflowing waters}

The waters flowing out of the marginal sea comprise a combination of modified boundary current water and convective waters formed in the interior of the marginal sea. As such, the temperature of the outflowing waters is required to lay between the temperature of the inflowing waters $\left(T_{1}\right)$ and the temperature of the water mass produced by deep convection $\left(T_{0}\right)$. A heat budget applied to the whole marginal sea balances the net heat flux into the basin with that lost to the atmosphere, and provides the additional constraint required to estimate the temperature of the outflowing waters:

$$
\begin{aligned}
\left(T_{1}-T_{\text {out }}\right) \Psi= & \frac{A \Gamma}{\rho_{0} C_{p}}\left[\left(1+P_{e} L / A\right)\left(T_{1}-T_{A}\right)\right. \\
& \left.-\left(T_{1}-T_{0}\right)\right] .
\end{aligned}
$$

This expression assumes that the outflowing mass transport is equal to the inflowing mass transport, defined as $\Psi=V_{1} H L$. Note that, because the vertical shear in the boundary current velocity is reduced within the marginal sea, to conserve mass in the marginal sea the velocity at the bottom of the outflowing boundary current must be southward, not zero as assumed for the inflowing boundary current. This rearrangement of the velocity 


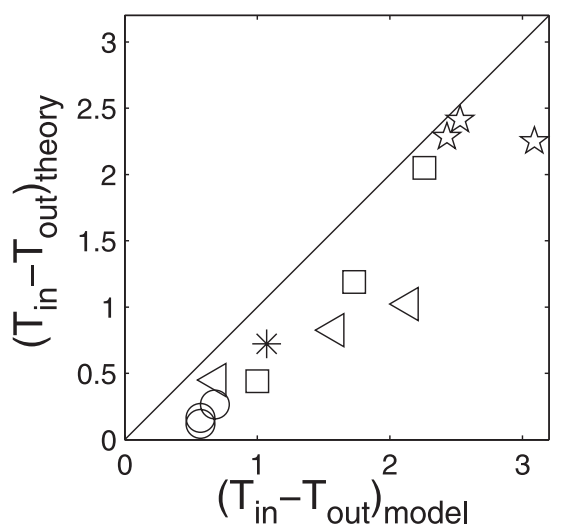

FIG. 9. A comparison of the diagnosed temperature difference $\left({ }^{\circ} \mathrm{C}\right)$ between the outflowing waters $\left(T_{\text {out }}\right)$ and the inflowing waters $T_{1}$ with the theory (17).

structure is used to estimate the net sinking in section $3 \mathrm{~d}$. Making use of (8), the change in temperature of the outflowing water compared to the inflowing water is

$$
T_{1}-T_{\text {out }}=2 \mu\left[\frac{T_{1}-T_{A}}{T_{1}-T_{0}}\left(1+P_{e} L / A\right)-1\right]\left(T_{1}-T_{A}\right) .
$$

The temperature anomaly of the outflowing water is calculated from the model runs and compared to that predicted by (17) in Fig. 9. The general trend is reproduced, but the theory consistently underpredicts the temperature anomaly of the outflowing water, perhaps related to the neglect of eddy fluxes across the sill in the theory. The outflowing water temperature depends on both $\mu$ and the ratio $\mu / \epsilon$, so a simple relationship with the nondimensional parameters is not easily presented.

The ouflowing waters are always warmer than the water formed in the interior of the basin. The fraction of the outflowing waters that include inflowing water can be estimated simply as

$$
\Delta=\frac{T_{\text {out }}-T_{0}}{T_{1}-T_{0}}=1-2 \mu\left[\frac{T_{1}-T_{A}}{T_{1}-T_{0}}\left(1+P_{e} L / A\right)-1\right] .
$$

This ratio is important for determining the net overturning in the marginal sea.

\section{d. Overturning in the marginal sea}

One aspect of the general circulation in convective basins relevant to climate is the overturning strength. This is often depicted by a zonal integral of the vertical velocity, producing an overturning streamfunction that represents the vertical mass transport as a function of latitude and depth. The overturning streamfunction for the central case is shown in Fig. 10. The maximum overturning strength at the latitude of the sill is $2.32 \mathrm{~Sv}$ $\left(\mathrm{Sv} \equiv 10^{6} \mathrm{~m}^{3} \mathrm{~s}^{-1}\right)$. This net sinking is largely confined to depths shallower than the sill. This is because the inflowing warm water is confined to depths above the sill. Convection reaches the bottom in the marginal sea, but there is little net vertical motion below the sill depth. Convection acts largely to mix the water vertically, but it does not contribute significantly to a net vertical volume flux (Spall 2004, 2010b).

An estimate of this overturning strength can be obtained by assuming that the inflowing and outflowing boundary currents are in thermal wind balance. It is required that the depth-integrated inflowing transport balance the depth-integrated outflowing transport. Because the outflowing temperature is less than the inflowing temperature, this requires that the vertical shear of the velocity of the outflowing water be less than that of the inflowing water. The amount of water that must downwell within the marginal sea to satisfy this constraint is given by the loss of transport in the upper half of the water column relative to the middepth of the boundary current, $\left(V_{1}-V_{\text {out }}\right) L H / 2$, where $V_{\text {out }}=\alpha g H\left(T_{\text {out }}-T_{0}\right) /$ $2 \rho_{0} f_{0} L$ is the baroclinic shear in the outflowing boundary

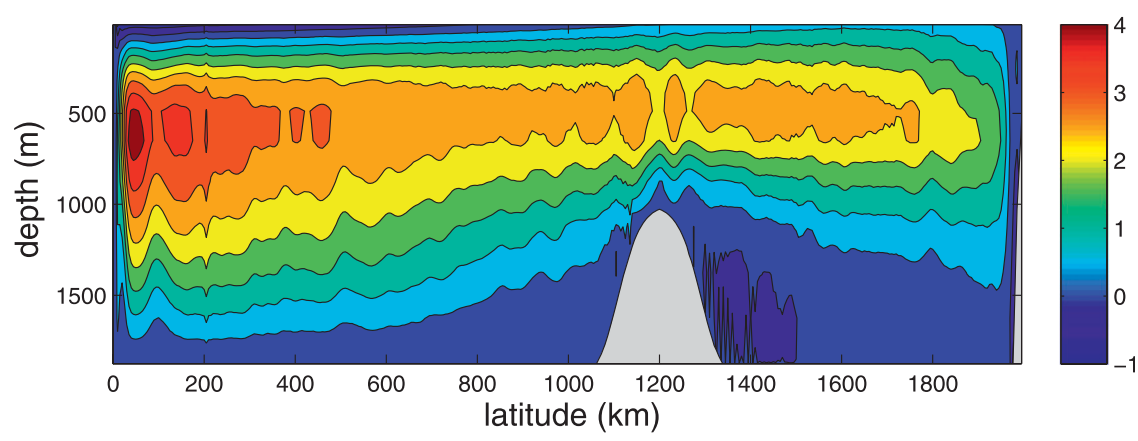

FIG. 10. The zonally integrated meridional overturning streamfunction for the central case $($ c.i. $=0.5 \mathrm{~Sv})$. The maximum value at the sill crest is $2.32 \mathrm{~Sv}$. 


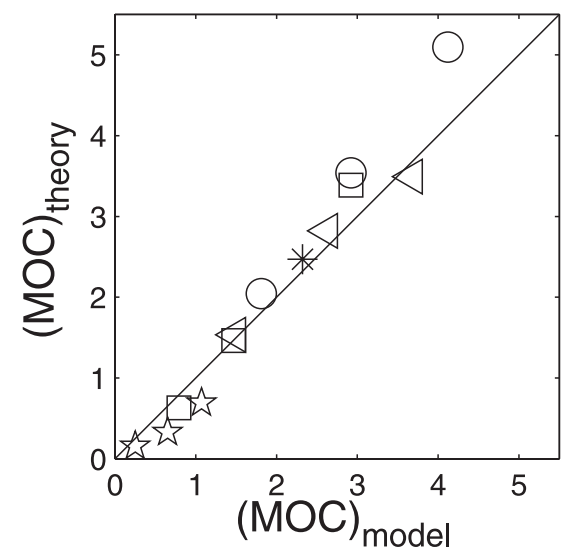

FIG. 11. Comparison of the strength of the meridional overturning streamfunction at the sill diagnosed from the model runs with the theory (19) $\left(10^{6} \mathrm{~m}^{3} \mathrm{~s}^{-1}\right)$.

current. Making use of (17) and assuming thermal wind balance, these constraints can be combined to estimate the net downwelling $W$ as

$W=\frac{\alpha g H^{2}\left(T_{1}-T_{0}\right)}{4 \rho_{0} f_{0}}(1-\Delta)=0.5 \Psi(1-\Delta)$,

where $\Psi$ is the horizontal transport in the boundary current and $\Delta$ is defined by (18). This downwelling takes place within the boundary current even though most of the heat loss and water mass transformation takes place in the basin interior. Transformation and sinking are two very different processes that are subject to different dynamical and thermodynamical constraints, although they are directly linked (Spall 2010b). For $\Delta=1, T_{\text {out }}=$ $T_{1}$ and there is no downwelling in the marginal sea. For $\Delta=0, T_{\text {out }}=T_{0}$ and half of the inflowing baroclinic transport sinks in the basin.

A comparison between the maximum meridional overturning streamfunction at the latitude of the sill and the prediction (19) is shown in Fig. 11. The theory compares well with the model results over the whole range of parameter space. The strength of the overturning varies between 0.25 and $4.12 \mathrm{~Sv}$. The strength of the overturning is most sensitive to the Coriolis parameter, the restoring time scale with the atmosphere, and the depth of the sill.

\section{e. Influence of wind forcing}

One of the outstanding issues regarding the meridional heat flux into the Nordic Seas is the relative influences of wind and buoyancy forcing. Although the numerical model is forced by both a surface heat flux and surface wind stress, the theory does not assume which is more important for forcing the mean flow. The idealized models of Spall (2004), Walin et al. (2004), Straneo (2006), and Iovino et al. (2008) ignored wind forcing completely. Deshayes et al. (2009) represented remote wind-forcing effects by altering the barotropic velocity component of the inflowing boundary current in an idealized basin with no sill. While these models have yielded useful results regarding the dynamics of such convective basins, their neglect of wind forcing was not justified on physical grounds, but instead provided a useful simplification. In the calculations of Straneo (2006), the idealized, buoyancy-only forced model was able to reproduce much of the observed seasonal and interannual variability in convection in the Labrador Sea, suggesting that wind effects were small. Jakobsen et al. (2003) note that there is a strong seasonal cycle in the winds, yet they find little seasonal cycle in the exchange across the sill. However, Orvik and Skagseth (2003) find an intriguing correlation between the wind stress curl at $55^{\circ} \mathrm{N}$ and the inflow to the Nordic Seas 15 months later along the eastern boundary at $62^{\circ} \mathrm{N}$. Their analysis suggests that baroclinic waves might be responsible for the time delay, but a detailed theoretical understanding of any relationship between wind forcing and transport into the Nordic Seas is currently lacking.

We can expect wind forcing to influence the exchange across the sill in several ways. While the following scaling analysis is fairly crude, it is a useful starting point to indicate what leading order effects might be expected owing to wind. First, there will be a meridional Ekman transport if there is a zonal component to the wind stress; its magnitude per unit zonal distance is given by

$$
v_{E}=\frac{-\tau^{x}}{\rho_{0} f_{0}}
$$

The sense of the transport is northward for winds to the west in the Northern Hemisphere. The anomalous temperature transport associated with this velocity is given by $v_{E} L_{x} \Delta T$, where $L_{x}$ is the zonal extent of the domain and $\Delta T=T_{s}-T_{0}$ is the temperature anomaly of the water just to the south of the sill compared to that in the interior of the convective basin. For parameters typical of the present model calculations, and the Nordic Seas, $v_{E} \approx 0.5 \mathrm{~m}^{2} \mathrm{~s}^{-1}$, and $L_{x}=10^{6} \mathrm{~m}$, which gives an Ekman mass transport of $0.5 \mathrm{~Sv}$ (Furevik and Nilsen 2005). This is much less than the transport across the sill, which is $O(8 \mathrm{~Sv})$ in both the model and the North Atlantic (Orvik et al. 2001). In addition, the waters in the interior to the south of the sill that are advected by the Ekman transport are colder than those transported along the eastern boundary, thus providing less heat transport for the same amount of mass transport. 
A second means by which the wind can force a heat transport into the northern basin is through the Sverdrupdriven interior flow. Cyclonic wind stress curl will force upwelling into the Ekman layer and drive a poleward response in the interior, below the Ekman layer. However, because the stratification is relatively weak at these latitudes, the topography cannot be neglected. Realistic sill configurations yield a topographic beta that is orders of magnitude larger than planetary beta, and suffiently large that the transport carried by the meridional Sverdrup flow across the sill is neglegible compared to the buoyancy-driven transport along the eastern boundary.

A third way in which the wind forcing can be important is if there is a northward wind stress along the eastern boundary. The Ekman transport associated with this stress will be toward the boundary and will result in an increased sea surface height on the boundary. The resulting pressure gradient will drive a northward flow along the boundary. For topographic contours that connect from the southern basin across the sill into the northern basin, this will provide a means to advect water from south of the sill directly into the northern basin. The transport in the boundary current will be determined primarily by the pressure anomaly on the boundary and the depth of the fluid.

An estimate of the strength of such a wind-driven boundary current can be obtained if we consider a wind toward the north that is of uniform strength $\tau_{0}^{y}$ north of a given latitude, arbitrarily defined as $y=0$, and zero south of that latitude. This is clearly an oversimplification, but is a useful idealization to consider the effects of meridional variability in the wind strength and the change in coastline orientation along the eastern boundary near $50^{\circ} \mathrm{N}$, approximately $1000 \mathrm{~km}$ south of the Iceland-Faroes sill. This is also approximately the distance from the sill to the southern boundary in the model, where the topographic contours run into the vertical wall.

The strength of the meridional flow resulting from this wind stress will be dependent on latitude because the forcing is confined to the region north of $y=0$ (e.g., Allen 1976; Middleton and Leth 2004). The steady meridional velocity at any latitude may be calculated by integrating the wind stress forcing along characteristics (here topographic contours) from $y=0$ to latitude $y$. For simplicity, stratification, friction, and nonlinearities are neglected. The steady solution is set up by a successive passing of coastal trapped waves, each higher mode propagating with a slower phase speed and contributing less to the total transport. An order of magnitude estimate of the strength of the boundary current is obtained by considering the first mode only. Following Allen (1976), integrating along the characteristic trajectories from $y=0$ to latitude $y$ gives the steady meridional transport as a function of latitude:

$$
V=\frac{y L \tau_{0}^{y}}{\rho_{0} c_{0}},
$$

where $L$ is the width of the unblocked geostrophic contours and $c_{0}$ is the barotropic shelf wave speed. For the case with a $1000-\mathrm{m}$ sill depth, $L=70 \mathrm{~km}, y=1200 \mathrm{~km}$, and $\tau_{0}^{y}=0.075 \mathrm{~N} \mathrm{~m}^{-2}$ and if we take a simple approximation for the barotropic shelf wave speed to be $c_{0}=$ $f_{0} L \approx 10 \mathrm{~m} \mathrm{~s}^{-1}$ (Brink 2006), this results in $0.62 \mathrm{~Sv}$ of wind-driven transport across the sill. This is an order of magnitude less than the total transport for this central case, once again suggesting that wind effects will be small. Because the characteristics propagate with shallow water on the right (in the Northern Hemisphere), wind stress within the marginal sea is not an effective means to "pull" water from the south across the sill, but it is possible to push water into the marginal sea from south of the sill by northward winds near the eastern boundary.

A series of model calculations are now carried out in which the strength of the wind forcing is varied. The central calculations in the previous section applied a cyclonic wind stress curl over the entire basin with a maximum wind stress of $0.15 \mathrm{~N} \mathrm{~m}^{-2}$. To test the sensitivity of the exchange between the marginal sea and the open ocean to the south, additional calculations with sill depths of $300,600,1000$, and $2000 \mathrm{~m}$ were carried out with $\tau_{0}^{x}=0$ and $\tau_{0}^{x}=0.3 \mathrm{~N} \mathrm{~m}^{-2}$. Note that these calculations apply a purely zonal wind, so the only wind effects expected are the direct Ekman transport and the Sverdrup transport.

The resulting temperature of the convective waters, meridional heat transport across the sill, and meridional overturning strength at the sill latitude are shown in Fig. 12. In each plot, the ordinate is the value in the absence of wind, while the abcissa is the value for various wind strengths and patterns. If the symbols fall along the diagonal line, the result with wind is the same as with no wind. For each sill depth, the properties of the exchange between the marginal sea and the open ocean are essentially the same, independent of wind strength.

To test the influence of wind parallel to the boundary, additional calculations were carried out with purely meridional winds given by $\tau_{0}^{y}=0.075,0.15 \mathrm{~N} \mathrm{~m}^{-2}, \tau_{0}^{x}=0$. These values give the same wind stress curl in the basin interior as the calculations with zonal wind stress and $\tau_{0}^{x}=0.15,0.3 \mathrm{~N} \mathrm{~m}^{-2}$. Once again, the characteristics of the exchange across the sill are nearly idential to that found with no wind. The transport into the marginal sea along the eastern boundary increases from 8.6 to $9.2 \mathrm{~Sv}$ to $9.7 \mathrm{~Sv}$ for $\tau_{0}^{y}=0,0.075,0.15 \mathrm{Nm}^{-2}$. This 

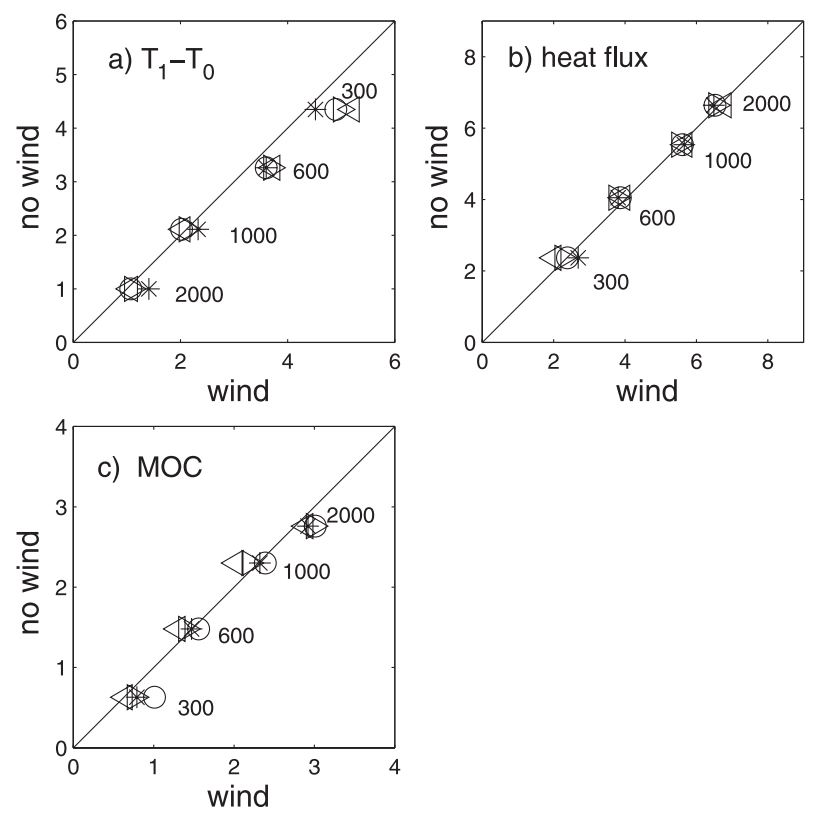

FIG. 12. Sensitivity to wind stress for (a) temperature anomaly of convective waters $\left({ }^{\circ} \mathrm{C}\right)$, (b) meridional heat flux across the sill $\left(10^{13} \mathrm{~W}\right)$, and $(\mathrm{c})$ meridional overturning streamfunction at the sill (Sv). Each symbol represents a calculation with a different wind forcing as $\tau_{0}^{x}=0.15 \mathrm{~N} \mathrm{~m}^{-2}$ (asterisk), $\tau_{0}^{x}=0.30 \mathrm{~N} \mathrm{~m}^{-2}$ (circle), and $\tau_{0}^{y}=0.075,0.15 \mathrm{~N} \mathrm{~m}^{-2}$ (triangles). The numbers next to each set of symbols are the sill depths.

increase with increasing wind stress parallel to the boundary is very close to that predicted above by integrating along the characteristics from the southern boundary.

These scaling and numerical results suggest that wind forcing is much less important than buoyancy forcing for the mean mass and heat transport from the subpolar gyre across the sill and into the marginal sea. It is worth reinforcing that we are concerned here with the mean exchange and heat transport. Wind is clearly important for the large-scale circulation in both the subpolar gyre and the marginal sea. It is also possible that the relative influences of wind and buoyancy forcing might be different for the variability of the mass and heat transport across the sill or if one takes salinity effects into account.

\section{Summary}

The mechanisms that determine the properties of the exchange between a marginal sea to the north of a subpolar gyre (relevant to the Nordic Seas and the subpolar North Atlantic) are explored using an idealized nonlinear primitive equation model and some simple theoretical concepts. Of particular interest are the meridional heat flux into the marginal sea, the strength of the meridional overturning circulation that results from heat loss in the marginal sea, the temperature of the convective water mass formed in the marginal sea, and the temperature of the waters exported from the marginal sea. A conceptual model is used to derive theoretical estimates of each of these properties of the exchange. The theory compares well with quantities diagnosed from a series of full nonlinear primitive equation model calculations. It is shown that all properties of the exchange are strongly influenced by competition between eddy fluxes from the edge of the marginal sea into its interior and heat loss from the interior of the marginal sea to the atmosphere. For relatively stable cyclonic boundary currents that encircle the marginal sea (or strong air-sea coupling) the convective water mass becomes very dense and the heat flux into the marginal sea approaches zero. For very unstable boundary currents the density of the interior water mass approaches that of the lighter waters outside the marginal sea and the heat flux into the marginal sea (and heat loss to the atmosphere) is maximum. Mesoscale eddies play a key role in this process because they are responsible for transporting heat from the narrow boundary current into the broad interior of the marginal sea, where it can then be lost to the atmosphere. The eddies are also partly responsible for driving the mean cyclonic boundary current that connects the marginal sea to the open ocean. Model experiments and scaling estimates indicate that the exchange is primarily driven by buoyancy forcing; wind effects are small. This eddy heat flux that determines the meridional heat transport into the marginal sea and the meridional overturning circulation will be difficult to represent in noneddy resolving climate models because the eddy heat flux (and decay) in the marginal sea is inherently nonlocal in nature.

Acknowledgments. This study was supported by the National Science Foundation under Grants OCE-0726339 and OCE-0850416. Any opinions, findings, and conclusions or recommendations expressed in this material are those of the author and do not necessarily reflect the views of the National Science Foundation. Fiamma Straneo is acknowledged for numerous fruitful discussions on a wide range of topics related to this work. Comments and suggestions from Johan Nilsson, Peter Rhines, and an anomymous reviewer helped to improve the presentation.

\section{REFERENCES}

Allen, J. S., 1976: Some aspects of the forced wave response of stratified coastal regions. J. Phys. Oceanogr., 6, 113-119.

Brambilla, E., and L. D. Talley, 2008: Subpolar mode water in the northeastern Atlantic: 1. Averaged properties and mean circulation. J. Geophys. Res., 113, C04025, doi:1029/2006JC004062. 
Brink, K. H., 2006: Coastal-trapped waves with finite bottom friction. Dyn. Atmos. Oceans, 41, 172-190.

Deshayes, J., F. Straneo, and M. A. Spall, 2009: Mechanisms of variability in a convective basin. J. Mar. Res., 67, 273-303.

Furevik, T., and J. E. O. Nilsen, 2005: Large-scale atmospheric circulation variability and its impacts on the Nordic Seas ocean climate-A review. The Nordic Seas: An Integrated Perspective, Geophys. Monogr., Vol. 158, Amer. Geophys. Union, 105-136.

Iovino, D., F. Straneo, and M. A. Spall, 2008: On the effect of a sill on dense water formation in a marginal sea. J. Mar. Res., 66, 325-345.

Isachsen, P. E., 2011: Baroclinic instability and eddy tracer transport across sloping bottom topography: How well does a modified Eady model do in primitive equation simulations? Ocean Modell., 39, 183-199.

, C. Mauritzen, and H. Svendsen, 2007: Dense water formation in the Nordic Seas diagnosed from sea surface buoyancy fluxes. Deep-Sea Res., 54, 22-41.

Jakobsen, P. K., M. H. Ribergaard, D. Quadfasel, T. Schmith, and C. W. Hughes, 2003: Near-surface circulation in the northern North Atlantic as inferred from Lagrangian drifters: Variability from the mesoscale to interannual. J. Geophys. Res., 108, 3251, doi:10.1029/2002JC001554.

Marshall, J., C. Hill, L. Perelman, and A. Adcroft, 1997: Hydrostatic, quasi-hydrostatic, and non-hydrostatic ocean modeling. J. Geophys. Res., 102, 5733-5752.

Middleton, J. F., and O. K. Leth, 2004: Wind-forced setup of upwelling, geographical origins, and numerical models: The role of bottom drag. J. Geophys. Res., 109, C12019, doi:10.1029/ 2003JC002126.

Nost, O. A., and P. E. Isachsen, 2003: The large-scale time-mean ocean circulation in the Nordic Seas and Arctic Ocean estimated from simplified dynamics. J. Mar. Res., 61, 175-210.
Orvik, K. A., and P. Niiler, 2002: Major pathways of Atlantic Water in the northern North Atlantic and Nordic Seas towards the Arctic. Geophys. Res. Lett., 29, 1896, doi:10.1029/2002GL015002.

— , and O. Skagseth, 2003: The impact of the wind stress curl in the North Atlantic on the Atlantic inflow to the Norwegian Sea toward the Arctic. Geophys. Res. Lett., 30, 1884, doi:10.1029/2003GL017932.

_ _ _ _ and M. Mork, 2001: Atlantic inflow to the Nordic Seas: Current structure and volume fluxes from moored current meters, VM-ADCP and SeaSoar-CTD observations, 19951999. Deep-Sea Res., 48, 937-957.

Poulain, P.-M., A. Warn-Varnas, and P. P. Niiler, 1996: Near surface circulation of the Nordic Seas as measured by Lagrangian drifters. J. Geophys. Res., 101, 18 237-18 258.

Smagorinsky, J., 1963: General circulation experiments with the primitive equations: I. The basic experiment. Mon. Wea. Rev., 91, 99-164.

Spall, M. A., 2004: Boundary currents and water mass transformation in marginal seas. J. Phys. Oceanogr., 34, 1197-1213.

_ 2010a: Non-local topographic influences on deep convection: An idealized model for the Nordic Seas. Ocean Modell., 32, $72-85$.

_ 2010b: Dynamics of downwelling in an eddy-resolving convective basin. J. Phys. Oceanogr., 40, 2341-2347.

Straneo, F., 2006: Heat and freshwater transport through the central Labrador Sea. J. Phys. Oceanogr., 36, 606-628.

Visbeck, M., J. Marshall, and H. Jones, 1996: Dynamics of isolated convective regions in the ocean. J. Phys. Oceanogr., 26, 17211734.

Walin, G., G. Broström, J. Nilsson, and O. Dahl, 2004: Baroclinic boundary currents with downstream decreasing buoyancy: A study of an idealized Nordic Seas system. J. Mar. Res., 62, 517-543. 